\title{
Fibronectin glomerulopathy
}

INSERM

\section{Source}

INSERM. (1999). Orphanet: an online rare disease and orphan drug data base. Fibronectin glomerulopathy. ORPHA:84090

Fibronectin glomerulopathy is a hereditary kidney disease characterized by proteinuria, type IV renal tubular acidosis, microscopic hematuria and hypertension that may lead to end-stage renal failure in the second to sixth decade of life. 